\title{
Etnomedisin Tetumbuhan Obat Tradisional Suku Serawai di Seluma, Bengkulu
}

\section{OJS}

Muhammad Adeng Fadila ${ }^{*}$, Nunik Sri Ariyanti², Eko Baroto Walujo ${ }^{2}$

${ }^{1}$ Department of Science Laboratory, Faculty of Mathematic and Natural Sciences, University of Bengkulu, Bengkulu 38371, Indonesia

${ }^{2}$ Department of Biology, Faculty of Mathematic and Natural Sciences, IPB University, Bogor 16680, Indonesia *E-mail:muhafad@unib.ac.id

DOI: https://doi.org/10.33369/pendipa.4.2.79-84

\begin{abstract}
[Ethnomedicinal plants of Serawai Tribe in Seluma, Bengkulu, Indonesia] Knowledge on traditional medicinal plants is generally closely related to the biodiversity, social, and culture of community. This study aims to inventory the diversity of plants that are recognized and used as traditional medicine by Tribe Serawai, and to analyze the local user value index (LUVI) of those medicinal plants. The study was conducted in four villages from four sub-districts in Seluma District, Bengkulu Province. Structured questionnaire and opened-answers questionnaire were applied for interviewing seven key informants and 232 respondents. Collecting and identifying specimen was conducted to confirm scientific name of the plant. The LUVI was calculated based on the score determined by respondents in a Focus Group Discussion (FGD). Total of 67 species consist of 62 genera and 32 families are recognized and utilized as medicinal plants by people of Tribe Serawai. The part of plant that are mostly used in Serawai's medicine is leaves. Other parts that used for the medicine are fruits, roots, barks, and seeds. The medicinal plants of Serawai are applied for curative agent and additives material. Most of the traditional medicine of Serawai Tribe are taken by rubbing, the others are used by oral, dropping and suppository. The LUVI of Serawai's medicinal plants are range from $0.01 \%$ to $0.32 \%$, the highest LUVI was obtained by a crop's plants.
\end{abstract}

Keywords: Additive medicinal plants; curative medicinal plant; ethnobotany; herbal medicine; traditional healer.

\begin{abstract}
ABSTRAK
Pengetahuan tentang tanaman obat tradisional umumnya terkait erat dengan keanekaragaman hayati, sosial, dan budaya masyarakat. Penelitian ini bertujuan untuk menginventarisasi keanekaragaman tanaman yang dikenali dan dimanfaatkan sebagai obat tradisional oleh Suku Serawai, dan untuk menganalisis indeks nilai pengguna lokal (LUVI) dari tanaman obat tersebut. Studi ini dilakukan di empat desa dari empat kecamatan di Kabupaten Seluma, Provinsi Bengkulu. Kuesioner terstruktur dan wawancara terbuka diterapkan untuk mewawancarai tujuh informan kunci dan 232 responden. Pengumpulan dan identifikasi spesimen dilakukan untuk mengkonfirmasi nama ilmiah tanaman. LUVI dihitung berdasarkan skor yang ditentukan oleh responden dalam Diskusi Kelompok Fokus (FGD). Total 67 spesies terdiri dari 62 genera dan 32 famili dikenali dan dimanfaatkan sebagai tanaman obat oleh masyarakat Suku Serawai. Bagian tanaman yang paling banyak dimanfaatkan dalam pengobatan Serawai adalah daun. Bagian lain yang dimanfaatkan untuk obat adalah buah, akar, kulit kayu, dan biji. Tetumbuhan obat tradisional Serawai diaplikasikan untuk obat kuratif dan aditif. Sebagian besar obat tradisional Suku Serawai diambil dengan cara dioles, yang lain digunakan secara oral, tetes dan supositoria. Indeks LUVI tanaman obat Serawai berkisar antara 0,01\% hingga $0,32 \%$ dengan LUVI tertinggi diperoleh oleh tanaman budidaya.
\end{abstract}

Kata kunci: Etnobotani; tetumbuhan obat kuratif; ethnobotany; obat herbal; penyehat tradisional.

\section{PENDAHULUAN}

Indonesia dikenal sebagai negara yang memiliki banyak suku dengan beranekaragam adat istiadat dan budaya, serta kearifan lokal. Salah satu kearifan lokal suku-suku di Indonesia yaitu, kepandaian dalam meramu obat tradisional dengan memanfaatkan tetumbuhan di sekitarnya. Obat tradisional ialah obat yang diolah dengan resep tradisional yang diwariskan oleh nenek moyang secara turun temurun (Supandiman dkk., 
2000). Sampai saat ini kebanyakan suku-suku di Indonesia masih mempraktikkan dan memanfaatkan tetumbuhan sebagai obat tradisional. Pengetahuan lokal ini dapat dijadikan sumber informasi tentang keanekaragaman tetumbuhan yang mempunyai manfaat sebagai obat tradisional (Sukara, 2007). Suatu kelompok suku dalam hal memanfaatkan tetumbuhan mempunyai kekhasan sesuai dengan kondisi kehidupan masyarakat (Suryadarma, 2010). Latar belakang budaya, kondisi geografis dan ketersediaan sumber daya hayati berpeluang membentuk keberagaman pengetahuan tentang pemanfaatan tetumbuhan sebagai obat tradisional. Oleh karena itu, jenis tumbuhan yang dimanfaatkan sebagai obat tradisional, bagian dan cara pemanfaatannya bervariasi antar suku, karena masing-masing suku memiliki kondisi biodiversitas, sosial dan budaya yang berbeda. Pengobatan tekanan darah tinggi oleh masyarakat di Lampung memanfaatkan daun alpukat (Evizal dkk., 2013), sementara suku Batin di Jambi me-manfaatkan akar kelapa, sedangkan suku Muna di Sulawesi Tenggara memanfaatkan daun kelapa (Jalius dan Muswita, 2013; Windadri dkk., 2006).

Banyaknya suku-suku di Indonesia dengan pengetahuan dan kearifan lokal memberi peluang dilakukan penelitian untuk mendokumentasikannya, termasuk di dalamnya adalah penelitian etnomedisin. Penelitian etnomedisin pernah dilakukan terhadap suku Serawai di Dusun Suka Bandung dan diperoleh sedikitnya 41 jenis tumbuhan obat (Adfa, 2005). Penelitian tersebut hanya dilakukan di satu desa dan menitikberatkan kepada aspek kandungan dan efek toksisitas bahan kimia dari tetumbuhan obat yang diteliti. Penelitian etnomedisin untuk menjelaskan aspek botani dan nilai kepentingan masing-masing jenis tumbuhan obat dalam Suku Serawai perlu dilakukan. Penelitian etnomedisin ini bertujuan menginventarisasi jenis tetumbuhan obat dan pemanfaatannya berdasarkan pengetahuan tradisional masyarakat suku Serawai, serta menganalisis nilai kepentingan jenis-jenis tumbuhan dalam pengobatan tradisional Suku Serawai.

\section{METODE PENELITIAN}

Penelitian lapangan dilaksanakan pada bulan Agustus 2015 hingga Februari 2018 di Kabupaten Seluma, Provinsi Bengkulu pada empat Desa, yaitu Desa Air Teras Kecamatan Talo, Desa Bakal Dalam Kecamatan Talo Kecil, Desa Dusun Baru Kecamatan Seluma dan Desa Jenggalu Kecamatan Sukaraja Data jenis tetumbuhan obat dan pemanfaatannya dikumpulkan melalui wawancara terstruktur dan wawancara bebas (open-ended interview) dengan melibatkan tujuh informan kunci dan 232 responden. Informan kunci dipilih berdasarkan keahlian dan luasnya pengetahuan mengenai tetumbuhan obat, misalnya penyehat tradisional (hattra) dan tetua adat (Walujo, 2004). Jumlah responden ditentukan berdasarkan 30\% dari jumlah kepala keluarga yang terdiri atas lakilaki dan perempuan berusia 15 - 45 tahun.

Pengumpulan spesimen tetumbuhan sebagai bahan identifikasi untuk konfirmasi secara ilmiah nama jenis tetumbuhan obat dilakukan bersama dengan informan kunci di lapangan melalui metode jelajah (Rugayah, dkk., 2004). Spesimen tumbuhan dibuat herbarium specimen voucher mengikuti prosedur standar (Djarwaningsih dkk., 2002; Rugayah dkk., 2004). Identifikasi nama ilmiah jenis tetumbuhan dilakukan dengan buku acuan (Medicinal Plants of Asia and the Pacific (Wiart, 2006); Indian Medicinal Plant (Khare, 2007); WHO Monographs on Selected Medicinal Plants volume 1-4 (WHO, 1999); WHO Monographs on Medicinal Plants Commonly Used in The Newly Independent States (NIS) (WHO, 2010) dan Life Science Identifie (LSID)/ Ilmuwan Identifikator). Kemudian status legitimasi nama jenis ditelusuri melalui laman The International Plant Name Index (IPNI) di www.ipni.org.

Focus Group Discussion (FGD) dilakukan bersama responden di masing-masing desa untuk mengonfirmasi pemanfaatan dan nilai kegunaan masing-masing jenis tetumbuhan obat. Konfirmasi pemanfaatan meliputi nama jenis tumbuhan, nama lokal, bagian yang dimanfaatkan, cara pemanfaatannya, perawakan, dan sifat penggunaannya. FGD juga dilakukan untuk memberi bobot pemanfaatan tumbuhan sebagai obat dibandingkan dengan pemanfaatan lainnya $\left(\mathrm{E}_{\mathrm{ij}}\right)$, bobot pemanfaatan bahan obat dari tumbuhan dibandingkan bahan lainnya $\left(\mathrm{P}_{\mathrm{ij}}\right)$, dan bobot pemanfaatan suatu jenis tumbuhan obat dibandingkan jenis tumbuhan obat lainnya $\left(\mathrm{C}_{\mathrm{J}}\right)$. Pemberian bobot oleh peserta FGD dilakukan dengan metode distribusi kerikil atau Pebble Distribution Methods (PDM). Hasil pemberian bobot pemanfaatan digunakan untuk menghitung indeks kepentingan masing-masing jenis tumbuhan obat bagi Suku Serawai (Local User's Value Index, LUVI) (Sheil dkk., 2004).

$$
\mathrm{LUVI}=\mathrm{G}_{\mathrm{ij}}=\mathrm{E}_{\mathrm{ij}} \times \mathrm{P}_{\mathrm{ij}} \times \mathrm{C}_{\mathrm{J}}
$$

Keterangan:

LUVI = nilai indeks kepentingan lokal

$\mathrm{G}_{\mathrm{ij}} \quad=$ nilai LUVI untuk spesies ke 1-n pada kegunaan ke 1-n.

$\mathrm{E}_{\mathrm{ij}} \quad=$ bobot untuk kategori kegunaan ke 1 
sampai kategori ke $\mathrm{n}(\mathrm{n}=8 ; 1$ bahan obat, 2 makanan utama, 3 makanan tambahan, 4 rempah, 5 ritual, 6 minuman, 7 kosmetik, 8 perabotan).

$\mathrm{P}_{\mathrm{ij}} \quad=$ Bobot bahan obat berasal dari bahan ke 1 sampai bahan ke $n(n=2 ; 1$ tumbuhan, 2 hewan).

$\mathrm{C}_{\mathrm{J}} \quad=$ Bobot jenis tumbuhan obat relatif terhadap jenis tumbuhan obat Lainnya.

\section{HASIL DAN PEMBAHASAN}

Tidak kurang dari 67 jenis tetumbuhan yang terdiri atas 62 marga dikenali dan dimanfaatkan oleh Suku Serawai sebagai bahan baku ramuan obat tradisional. Jenis-jenis tetumbuhan yang dimanfaatkan sebagai obat oleh Suku Serawai berasal dari 32 suku tetumbuhan berbunga (66 jenis) dan paku-pakuan (Blechnum occidentale), paling banyak berasal dari suku Asteraceae (7 jenis), kemudian Fabaceae (6 jenis), dan Poaceae (5 jenis). Jenis-jenis tumbuhan yang dilaporkan dimanfaatkan untuk ramuan obat tradisional oleh berbagai kelompok etnis di dunia juga kebanyakan dari tiga suku tumbuhan tersebut (Lira dkk., 2009; Sakkir dkk., 2012; Al-Sodany dkk. 2013; Kindscher dkk., 2013; dan Zizka dkk., 2015). Sebanyak 11 jenis diantaranya telah dilaporkan pemanfaatannya sebagai obat tradisional masyarakat Suku Serawai (Adfa, 2005), yaitu Annona muricata, Averrhoa bilimbi, Bambusa vulgaris, Datura metel, Elephantopus scaber, Graptophyllum pictum, Lantana camara, Melastoma malabathricum, Ocimum basilicum, Tamarindus indica, dan Urena lobata. Meskipun demikian, penelitian ini menambahkan penggunaan yang berbeda dari laporan sebelumnya, antara lain Elephantopus scaber dimanfaatkan untuk obat gatal dan jerawat (Adfa, 2005), penelitian ini menambahkan informasi pemanfaatannya sebagai obat perut kembung.

Pemanfaatan tetumbuhan obat oleh Suku Serawai dikelompokkan dalam tiga kategori (Gambar 1), yaitu untuk mengobati penyakit (kuratif), mencegah penyebaran penyakit (preventif), dan menjaga stamina (aditif). Senyawa metabolit sekunder dari beberapa tumbuhan obat telah dilaporkan misalnya, bunga rorella (Hibiscus sabdariffa) mengandung saponin, flavonoid, tanin, fenol, glikosida dan alkaloid (Okereke dkk., 2015). Masyarakat Suku Serawai memanfaatkan air rebusan bunga rosella untuk menjaga daya tahan tubuh, sementara Masyarakat Lampung memanfaatkan Brotowali (Evizal dkk., 2013). Penelitian melaporkan ekstrak ethanol awar-awar (Ficus septica) dapat meningkatkan sistem imun pada percobaan menggunakan tikus sehingga berpotensi sebagai obat pendamping untuk kemoterapi (Sari dkk., 2015). Berdasarkan pengetahuan Suku Serawai, air rebusan kulit batang awar-awar yang diberikan kepada penderita kanker dipercaya dapat mencegah penyebaran kanker.

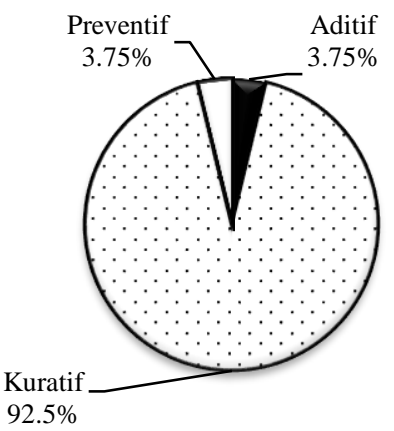

Gambar 1. Grafik persentase tetumbuhan obat tradisional berdasarkan pemanfaatannya

Suku Serawai paling banyak menggunakan daun sebagai bahan pembuatan ramuan obat tradisional. Daun sebagai bahan yang paling sering dimanfaatan sebagai obat juga dilaporkan pada berbagai suku di dunia (Sakkir dkk., 2012; Bhat 2014; Chukwuma dkk., 2015; Zizka dkk., 2015). Penelitian terdahulu melaporkan bahwa daun lebih banyak mengandung senyawa flavonoid dibandingkan bagian lainnya, dikarenakan daun lebih banyak mengandung keragaman flavonoid yang umumnya berfungsi sebagai antioksidan dan antimikroba (Pambudi dkk., 2014). Selain itu dari aspek pelestarian tumbuhan, pemanenan daun dianggap lebih efisien mengingat daun akan segera tumbuh kembali jika dibandingkan dengan pemanenan akar yang secara tidak langsung membuat tumbuhan mati, atau pemanenan buah dan biji yang harus menunggu masa perbungaan dahulu.

Masyarakat Serawai umumnya memanfaatkan ramuan obat tradisional dengan cara mengoleskan, meminum, meneteskan dan memasukkan ramuan obat tradisional melalui lubang anus (Gambar 2). Hal serupa dilaporkan bahwa cara yang paling lazim digunakan untuk pemanfaatan tumbuhan obat ialah dengan dioles dan oral (Adfa 2005; Evizal dkk., 2013). Ramuan obat tradi-sional dimanfaatkan dengan cara yang berbeda ditujukan untuk mengobati penyakit sesuai dengan lokasi penyakitnya. Ramuan obat tradisional dengan cara mengoleskan umumnya diperuntukan untuk obat luar, seperti penyakit kulit, sementara ramuan obat tradisional yang dimanfaatkan dengan diminum pada umumnya ditujukan untuk mengobati penyakit dalam. Ramuan obat tradisional dalam bentuk obat tetes 
dimanfaatkan untuk meredakan infeksi atau iritasi pada mata dan telinga, sementara obat yang dimasukkan melalui dubur dimanfaatkan untuk menyembuhkan ambeien.

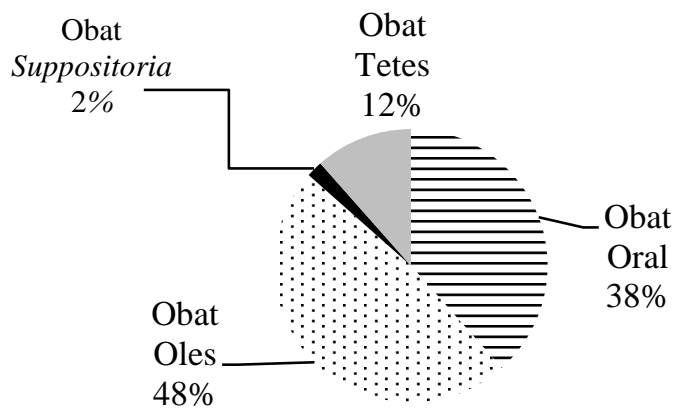

Gambar 2. Grafik persentase cara pemanfaatan obat tradisonal

Indeks kepentingan lokal jenis tetumbuhan obat suku Serawai berkisar dari $0.01 \%$ sampai $0.32 \%$, dengan padi (Oryza sativa) dinilai dengan LUVI tertinggi $(0.32 \%)$ dalam pengobatan tradisional Suku Serawai. Padi merupakan sumber makanan pokok bagi kebanyakan masyarakat Indonesia, termasuk Suku Serawai. Suku Serawai sendiri membudidayakan padi sebagai mata pencaharian utama. Padi digunakan untuk mengobati sakit kuning, asam urat, dan demam. Ada lima jenis tumbuhan obat lainnya yang memperoleh indeks kepentingan lebih dari $0.20 \%$, yaitu pisang kepok (Musa $\times$ paradisiaca), kelapa (Cocos nucifera), pisang mas (Musa acuminata), dan jahe (Zingiber officinale). Daun pisang mas dan pisang kepok selain bermanfaat sebagai obat, batang, buah, dan jantungnya dimanfaatkan sebagai makanan utama maupun tambahan. Bagian batang dan jantung dikonsumsi dengan mengolahnya terlebih dahulu sementara buahnya dapat langsung dimakan maupun diolah terlebih dahulu. Suku Serawai memanfaatkan tanaman kelapa untuk berbagai keperluan, minyak kelapa oleh suku Serawai dimanfaatkan sebagai obat urut, daunnya untuk membuat ketupat dan sapu lidi, selanjutnya bara dari batok kelapa dimanfaatkan untuk memasak dan sumber panas untuk setrika tradisional, sementara batang kelapa dimanfaatkan untuk membangun rumah. Jahe oleh Suku Serawai dimanfaatkan sebagai obat dan rempah untuk memasak. Indeks kepentingan jenis-jenis tumbuhan obat lainnya berkisar dari $0.01 \%$ sampai $0.20 \%$. Umumnya jenis-jenis tumbuhan obat dengan nilai LUVI tinggi merupakan tumbuhan yang sudah dibudidaya dan tidak hanya dimanfaatkan sebagai obat, tetapi juga memiliki banyak kegunaan lainnya. Tumbuhan obat berperawakan herba yang merupakan tumbuhan liar atau gulma semuanya memiliki nilai LUVI rendah $(<0.03)$. Ageratum conyzoides bermanfaat sebagai obat sembelit dinilai tidak terlalu penting karena beberapa masyarakat menganggap tumbuhan tersebut kurang bermanfaat bagi kehidupan mereka sehari-hari sementara masyarakat lainnya tak begitu mengenalinya, berlaku juga bagi Lantana camara yang untuk obat kembung dan Bidens pilosa untuk obat iritasi mata.

Berdasarkan daftar merah IUCN (Gambar 3) didapatkan tiga jenis tumbuhan dalam status risiko rendah (least concern), yaitu jeringau (Acorus calamus), talas (Colocasia esculenta), dan tapak liman (Elephantopus scaber). Penggunaan ketiga jenis tersebut berdasarkan indeks kepentingan lokal dinilai cukup rendah oleh masyarakat Serawai, hal ini dibuktikan dengan nilai LUVI dari jenis Acorus calamus (0.02\%), Colocasia esculenta $(0.09 \%)$, dan Elephantopus sacber $(0.03 \%)$. Sedangkan 64 jenis lainnya belum dievaluasi (not evaluated). Status konservasi risiko rendah (least concern) sendiri berarti jenis tumbuhan tersebut kelimpahannya masih belum mengkhawatirkan, namun tetap memerlukan langkah pencegahan dini, begitu juga untuk jenis lainnya yang belum dievaluasi bisa dimulai untuk mengevaluasinya.

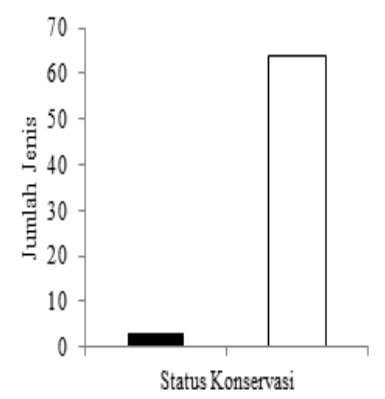

Status konservasi berdasarkan daftar merah IUCN berupa Risiko rendah dan Belum dievaluasi ( $\square$ )

Gambar 3. Grafik jumlah jenis tetumbuhan obat tradisional berdasarkan status konservasi

Seringkali di berbagai tempat, eksploitasi tumbuhan obat dilakukan secara besar-besaran dengan cara pemanenannya tanpa memperhatikan aspek pelestariannya. Contohnya eksploitasi purwoceng (Pimpinella pruatjan) di Taman Nasional Bromo Tengger Semeru (TNBTS) yang dipanen dari habitat alaminya, sehingga akhirakhir ini kondisinya cukup mengkhawatirkan. Jenis ini merupakan jenis dengan kategori punah di alam (extinct in wild), karena tidak ditemukan di habitat aslinya (Hidayat dan Risna, 2007). Khusus untuk jenis-jenis yang dinyatakan langka, 
unik dan endemik pemerintah Indonesia berkepentingan untuk meratifikasi Protokol Nagoya melalui Undang-Undang Republik Indonesia Nomor 11 tahun 2013. Protokol Nagoya merupakan protokol mengenai akses pada sumber daya genetik dan pemanfaatan keanekaragaman hayati. Melalui ratifikasi ini pemerintah Indonesia mendorong pemanfaatan sekaligus pelestarian keanekaragaman hayati serta pengetahuan dan kearifan lokal masyarakat Indonesia.

\section{KESIMPULAN}

Masyarakat Suku Serawai di Seluma mengenal 67 jenis tetumbuhan yang dimanfaatkan dalam pengobatan tradisional, yang terdiri atas 62 marga dan 32 suku. Jenis-jenis tumbuhan tersebut paling banyak dimanfaatkan bagian daunnya (39 jenis), kemudian berturut-turut jenis-jenis yang dimanfaatkan buah, akar, kulit batang, dan bijinya. Sebagian besar jenis-jenis tumbuhan obat (90\%) yang dikenali oleh masyarakat digunakan untuk penyembuhan penyakit (kuratif). Penggunaan bahan obat dari jenis-jenis tumbuhan obat lainnya (masing-masing sebesar 5\%) bersifat aditif dan preventif. Cara pemanfaatan obat tradisional yang paling lazim ialah dioleskan (48\%), berikutnya berturut-turut pemanfaatan oral (38\%), diteteskan (12\%), dan supossitoria (2\%). Berdasarkan status konservasi tetumbuhan obat tradisional etnis Serawai terdapat tiga jenis tetumbuhan dalam status risiko rendah (least concern), yaitu jeringau (Acorus calamus), talas (Colocasia esculenta), dan tapak liman (Elephantopus scaber). Nilai LUVI tetumbuhan obat tradisional Suku Serawai berkisar 0.01\%$0.32 \%$, dengan nilai LUVI tertinggi ialah padi.

\section{DAFTAR PUSTAKA}

Adfa M. 2005. Survey etnobotani, studi senyawa flavonoid dan uji brine shrimp beberapa tumbuhan obat tradisional Suku Serawai di Provinsi Bengkulu. Gradien 1(1), 43-50.

Al-Sodany YM, Salih, Bazaid A, Mossalam HA. 2013. Medicinal Plants in Saudi Arabia: I. Sarrwat Montains at Taif, KSA. AJPS 6(4), 134-145.

Bhat RB. 2014. Medicinal plants and traditional practices of Xhosa people in the Transkei region of Eastern Cape, South Africa. Academic Journal of Plant Sciences 6(4), 134-145.

Chukwuma EC, Soladoye MO, Feyisola RT. 2015. Traditional medicine and the future of medicinal plants in Nigeri. JMPS 3(4), 23-29.

Djarwaningsih T, Sunarti S, Kramadibrata K. 2002. Panduan Pengolahan dan Pengelolaan
Material Herbarium serta Pengendalian

Hama Terpadu di Herbarium

Bogoriense.Bogor (ID): LIPI Pr.

Evizal R, Setyaningrum E, Ardian, Wibawa A, Aprilani D. 2013. Keragaman Tumbuhan dan Ramuan Etnomedisin Lampung Timur. Prosiding Semirata FMIPA Universitas Lampung; 2013; Lampung, Indonesia. Lampung (ID). 279-286.

Hidayat S, Risna RA. 2007. Kajian Ekologi Tumbuhan Obat Langka di Taman Nasional Bromo Tengger Semeru. Biodiversitas 8(3), 169-173.

Jalius, Muswita. 2013. Eksplorasi pengetahuan lokal tentang tumbuhan obat di Suku Batin, Jambi. Biospecies 6(1), 28-37.

Khare CP. 2007. Indian Medicinal Plants. New York (US): Springer.

Kindscher K, Corbett S, McClure K. 2013. A statistical analysis of medicinal plants: A case study of plant families in Kansas and the Great Plains. TKAS 116(3-4), 149-155.

Lira R, Casas A, Rosas-Lopez R, Paredes-Flores M, Perez-Negron E, Rangel-Landa S, Solis L, Torres I, Davila P. 2009. Traditional knowledge and useful plant richness in the Tehuacan-Cuicatlan Valley, Mexico. Economic Botany 20(10), 1-17.

Okereke CN, Iroka FC, Chukwuma MO. 2015. Phytochemical analysis and medicinal uses of Hibiscus sabdariffa. IJHM 2 (6), 16-19

Pambudi A, Syaefudin, Noriko N, Swandari R, Azura PR. 2014. Identifikasi bioaktif golongan flavonoid tanaman anting-anting (Acalypa indica L.). J Al-Azhar Indonesia 2(3), 178-187.

Rugayah, Widjaja EA, Praptiwi. 2004. Pedoman Pengumpulan Data Keanekaragaman Flora. Bogor (ID): LIPI Pr.

Sakkir S, Kabshawi M, Mehairbi M. 2012. Medicinal plants diversity and their conservation status in the United Arab Emirates (UAE). Journal of Medicinal Plants Reasearch 6(7), 1304-1322.

Sari DI, Yazin AH, Anovia RA, Ismayani U, Darmawan E. 2015. Peningkatan sistem imun oleh kombinasi ekstrak etanol daun awarawar (Ficus septica burm. F) dan ekstrak etanol daun kelor (Moringa oleifera) sebagai ko-kemoterapi kanker pada tikus putih betina galur Sprague Dawley yang diinduksi Doksorubisin. Pharmaçiana. 5(2), 147-152.

Sheil D, Puri RK, Basuki I, Heist MV, Wan M, Liswanti N, Rukmiyati, Sardjono MA, Samsoedin I, Sidiyasa K et al. 2004. Mengeksplorasi Keanekaragaman Hayati 
Lingkungan dan Pandangan Suku Lokal Mengenai Berbagai Lanskap Hutan. Bogor (ID): Central for International Forestry Research.

Sukara E. 2007. Bioprospecting dan Strategi Konservasinya.Prosiding Seminar Tumbuhan Usada Bali dan Peranannya dalam Mendukung Ekowisata; 2007 Sept 6; Bali, Indonesia. Bogor (ID): LIPI Pr. 1-7.

Supandiman I, Muchtar, Sidik. 2000. Keamanan Pemakaian Obat Tradisional dalam Pelayanan Klinik. Prosiding Kongres Nasional Obat Tradisional Indonesia:Simposium Penelitian Bahan Obat Alami X; 2000 Nop 20-22; Surabaya, Indonesia. Surabaya (ID). Sentra P3T. 1-11.

Suryadarma IGP. 2010. Keanekaragaman tumbuhan bahan kebugaran dalam naskah lontar Rukmini Tatwa Suku Bali. Biota 15(2), 294-305.

Walujo EB. 2004. Pengumpulan Data Etnobotani. Di dalam: Rugayah. Widjaja EA., Praptiwi, editor. Pedoman Pengumpulan Data Keanekaragaman Flora. Bogor (ID): LIPI Pr. 77-92.
Wiart C. 2006. Medicinal Plants of Asia and the Pacific. Massachusetts (US): CRC Pr.

Windadri FI, Rahayu M, Uji T, Rustiami H. 2006. Pemanfaatan tumbuhan sebagai bahan obat oleh suku lokal Suku Muna di Kecamatan Wakarumba, Kabupaten Muna, Sulawesi Tenggara. Biodiversitas 7(4), 333-339.

[WHO] World Health Organization. 1999. WHO Monographs on Selected Medicinal Plants. Volume ke-1. Geneva (CH): WHO Pr.

[WHO] World Health Organization. 2010. WHO Monographs on Medicinal Plants Commonly Used in the Newly Independent States (NIS). Geneva $(\mathrm{CH})$ : WHO Pr.

Zizka A, Thiombiano A, Dressler S, Nacoulma BMI, Ouedraoga A, Ouedraogo I, Ouedraogo O, Zizka G, Hahn K, Schmidt M. 2015. Traditional plant use in Burkina Faso (West Africa): a national-scale analysis with focus on traditional medicine. JEE 11(9), 1-10. 